\title{
On Marketing Modes of ICBEC Based on 4C Principles - A Case Study of Mia
}

\author{
Yu He and Jing Li* \\ Xinhua College of Sun Yat-sen University, China \\ ${ }^{*}$ Corresponding author
}

\begin{abstract}
The marketing modes of Import-oriented Cross-border E-commerce (ICBEC) are popping up at an unprecedented pace in recent years under the attraction of the huge market and with Chinese people's increasing demands for overseas products. Therefore, the ever-growing competition among ICBEC has pushed the accurate marketing and differentiation strategy into the spotlight. This paper, beginning with an overview of current marketing modes of IOCBEs and the challenges they are faced with, is to analyze Mia's Consumer-oriented Policy and its marketing strategy based on 4C principles.
\end{abstract}

\section{Keywords-ICBEC; 4C, Mia; consumer-oriented}

\section{INTRODUCTION}

As the vigorously rapid development of global economic integration and Internet, with frequent expansion of business activities realized between different nations and regions relying on Internet and relevant information technology platforms, CBEC gradually becomes a new type of business in international trade. The recent years have witnessed Chinese people's increasing demands for overseas products. As professional purchasing agents and some professional e-commerce platforms springing up, Import-oriented Cross-border E-commerce (hereinafter referred to as ICBEC) finds its way to boom.

CBEC (hereinafter referred to as CBEC) satisfies users' demands and promotes the development of China's foreign trade economy as well. However, as the increasingly fierce competition of CBEC, more and more CBEC participants start to seek for differentiated development routes. In particular, they take advantage of connections in between many platforms online to collect data and identify demand, realize fair promotion of products through extraction and mining of big data, promote optimization of product design and find solutions to unbalanced product supply and demand. Simply speaking, it is a "consumer-oriented" mode, C-end becoming the front-end, truly guided by integrated marketing 4C.

4C is a modern marketing method put forward by Don Schultz, a US marketing professor in the 1990s when the sellers' market turned into the buyers' market. It promotes $4 \mathrm{C}$ strategy, i.e., consumers' demand (Consumer), cost satisfying consumers' demand (Cost), convenience for purchasing channels (Convenience) and capacity of communication (Communication). 4C has huge differences with the traditional $4 \mathrm{P}$ in the following ways: a) "consumer" requires more attention to consumers' demand and desires than "product", and it works to provide products satisfying consumers' demand and desires; b) "cost" pays more attention to possible costs for consumer to satisfy his or her demands and desires than "price"; c) "convenience" takes consumer's purchasing convenience into consideration than "channel"; d) "communication" cares more about communication with consumer than "promotion".

\section{OVERVIEW OF ICBECS}

CBEC is an international business activity with its trading subjects belonging to different customs areas, which make transactions and make payment and settlement via electronic commerce platform and deliver commodities by cross-border physical distributions to complete the transaction. CBEC can be divided into import-oriented type and export-oriented type according to import and export cargo distributions.

In terms of ICBEC, there are import e-commerce enterprises according to platforms relied on by imported products selling: bonded self-built platforms like Zhengzhou bonded cross-border trading platforms, vertical e-commerce platform like Miyababy, third-party platforms like Tmall Globe, JD Globe; offshore shopping platforms: overseas websites like direct shopping on Amazon and Ralphlanren; purchasing agent platform: individual purchasing platforms of overseas products like Weibo or WeChat.

ICBEC experienced a tough and long development process in China. Cross-border shopping of Chinese consumers started from 2005, when scattered human expresses and offshore direct mails were used at the very first beginning, before the establishment of offshore commodity shopping platforms. Domestic e-commerce giants rose rapidly in the field relying on its existing advantages. Therefore, China's cross-border import experienced individual purchasing, purchasing systematization, overseas shopping and import retail e-commerce. As the booming of retail e-commerce, the whole industry develops vigorously. Overseas shopping and individual purchasing have shortcomings in sources, price, logistics and service, sparing space for development of import retail e-commerce trade.

Currently as it is at the stage of ICBEC, the operation modes for such platforms are mainly divided into vertical self-operation, comprehensive self-operation and vertical platforms and comprehensive platforms, as shown in Fig.1. 


\begin{tabular}{|l|l|l|}
\multicolumn{2}{c}{ Self-operation } \\
\cline { 2 - 3 } Comporehensive & $\begin{array}{l}\text { Kaola.com } \\
\text { Amazon.cn } \\
\text { Xiaohongshu.com }\end{array}$ & $\begin{array}{l}\text { Mia.com } \\
\text { Gou.com } \\
\text { VIP.vom } \\
\text { Jumeiglobal.com }\end{array}$ \\
\cline { 2 - 3 } & $\begin{array}{l}\text { JDWorldwide.com } \\
\text { Tmall.HK } \\
\text { G.Taobao.com } \\
\text { Ymatou.com }\end{array}$ & Lehe.com \\
\hline \multicolumn{2}{|c|}{ Platform } \\
\hline
\end{tabular}

FIGURE I. CLASSIFICATIONS OF ICBEC

Vertical self-operation platforms mainly focus on vertical products or vertical groups like infants \& moms, beauty, to classify and sell commodities. Most are self-operated B2C with small proportion of M2C as supplement, like mia.com, vip.com; comprehensive self-operation has rich commodity and capital resources. Part of e-commerce changes from vertical type into comprehensive type after a period of development, like Amazon; vertical e-commerce participants are limited, mainly concentrated on vertical products like clothes and beauty. Mostly, it is a C2C mode, like meilishuo.com. Comprehensive platform e-commerce operates with large variety and comprehensive products; its main players are internal trade e-commerce giants, who take their strong flow advantage to attract consumers. It includes B2C and $\mathrm{C} 2 \mathrm{C}$ modes, such as Tmall and ymatou.com.

Main business of CBECimport enterprises cover infant \& mom products, beauty and skin care, clothes, shoes and bags, food \& health care and life digital, barely uncovering every corner of our life, as shown in Table 1.

TABLE I. OPERATION AND PRODUCT CLASSIFICATIONS OF ICBEC

\begin{tabular}{|c|c|c|}
\hline $\begin{array}{l}\text { ICBEC } \\
\text { platforms }\end{array}$ & Operation modes & Commodity varieties \\
\hline Tmall & $\begin{array}{l}\text { Third-party platform/ } \\
\text { comprehensive }\end{array}$ & Comprehensive varieties \\
\hline Amazon & \multirow{2}{*}{$\begin{array}{l}\text { Self-operated/ } \\
\text { comprehensive }\end{array}$} & Comprehensive varieties \\
\hline $\begin{array}{l}\text { Kaola.co } \\
\text { m }\end{array}$ & & Quality products \\
\hline JD.com & $\begin{array}{l}\text { Platform + self-operated/ } \\
\text { comprehensive }\end{array}$ & Comprehensive varieties \\
\hline Mia.com & \multirow{3}{*}{ Self-operated/vertical } & Infant \& mom products \\
\hline VIP.com & & $\begin{array}{l}\text { Beauty, } \\
\text { Infant \& mom products, } \\
\text { clothes }\end{array}$ \\
\hline $\begin{array}{l}\text { JUMEI } \\
\text { global.co } \\
\text { m }\end{array}$ & & $\begin{array}{l}\text { Beauty, } \\
\text { Infant \& mom products, } \\
\text { clothes }\end{array}$ \\
\hline
\end{tabular}

\section{ANALYSIS ON CURRENT SITUATION AND THE} DEVELOPMENT OF MIA

As the development of internet, e-commerce penetration rate in China import trade increases consistently. According to iResearch, market trade of ICBEC reached RMB 900 billion in 2015 , increasing by $38.5 \%$ with a penetration rate of $8.6 \%$. In 2016, the overall trade (including retail and B2B) of import and export-oriented CBEC reached RMB 6,300 billion. By 2018, the overall trade of import \& export e-commerce is expected to reach RMB 8,800 billion. According to analyzers of iResearch, China's CBEC platforms for import retail gradually sprung up recent years. They are getting more shares in import \& export CBEC trade scale by enhancing users' experience in fierce competition and promoting China's CBEC trade scale in import retail to develop steadily. In the last two years, the mostly financed enterprises in ICBEC are in the mode of self-operated B2C, followed by platform C2C. In terms of variety distribution, it is mostly of vertical type, focusing on several hot varieties of overseas shopping: infant \& mom, beauty, fashion, food, health care products, etc.

From 2010 to 2014, the overseas shopping trading amount of China has been increased from over RMB 10 billion to over RMB 80 billion, milk power and diapers taking 18\%, nearly RMB 15 billion. According to iResearch, China's infant \& mom market saw a breakthrough of RMB 2,000 billion in 2015, taking $6.8 \%$ of the total amount of social consumption, with $15.5 \%$ online penetration rate. It is expected to be a blow-out development in infant \& mom online shopping market in the next few years. Large B2C e-commerce businesses like Ali, JD and Amazon have set their feet in the cross-border market with strong capacity, vertical e-commerce platforms like mia.com, xiaohongshu.com, ymatou.com and kaola.com are actively snatching market share and a large number of cross-border infant \& mom e-commerce platforms have seen a rapid rise in 2015. In the last 2 years, financing market in ICBEC industry are active, maintaining a monthly average 1-2 financing transaction(s); currently, the industry comes with a unicorn enterprise - mia.com, far surpassing other enterprises' estimated price.

"Mia" is originated from the taobao store "miyababy", which was started by Liu Nan mainly selling infant \& mom products in 2011. It was operated into four crowns, exceeding sales amount of RMB 30 million. In March 2014, cross-border vertical infant \& mom special offer platform "miyababy" was officially launched, with Ningbo and Guangzhou bonded warehouse added and overseas warehouse in Germany, Netherlands and Australia provided. At the end of 2014, it got 3 waves of financing. In April 2015, miyababy and RYB Education Institution, China children education leading brand, announced establishment of joint venture with Mia.com providing cross-border supply chain, since then it had opened offline channel in over 1,300 kindergartens all over 300 cities via RYB. In July 2015, Miyababy became mia.com, and was upgraded into a "mother \& child family purchase platform". It had finished its D-wave financing in September 2015 of USD 150 million, with an estimated value of more than USD 1 billion, making Mia the largest infant \& mom e-commerce platform in China. In December 2016, it completed its new financing. Within only 3 years since its online operation in March 2014, it rose sharply, no matter in its development or influence, making it an inevitable sample in e-commerce research.

Mia.com gets its goods from four channels: brand domestic general agent, offshore direct mail purchase, bonded import and general import trading, making it a professional import-oriented infant \& mom product CBEC. As a self-operated vertical ICBEC enterprise, it is required to fully participate in the operation of the whole process, including pre-sale selection, supplier negotiation, operation and in-depth management of logistics and services. The biggest advantage of 
mia.com first relies in its location in overseas shopping of hot infant \& mom products and its profession in understanding and deepening services of vertical groups, being able to dig out popular overseas products in vertical varieties. Plus its reputation, social breeding demand and social promotion, so its product selection capacity and conversion rate are very high.

\section{Analysis on Marketing Mode of 4C-BASED MIA.COM}

\section{A. Grasp Consumer's Needs and Wants}

4C first emphasizes consumers' demands and desires. Final success can be realized only with deep understanding of consumer's real demand and desire. Therefore, enterprises needs to center on customers in design of products and even in the whole process of selling. Miyababy, in this regard, understands and seizes user's demand by various means.

1) Understand infant \& mom's demand for products - high quality and inexpensive by making full use of big data: According to iResearch, on B2C platform in 2015, Wyeth, Friso and MeadJohnson were the top three milk powder brands with the highest trading amount; Huggies, $24.0 \%$ in sales was the first in diaper trading amount, followed by Merries and Pampers. Foreign-invested brands still have monopoly advantage, which is to say that domestic consumers still prefer overseas brands. Mia.com takes this as an opening point, mainly selling milk powders and diapers from these brands.

iResearch also shows that beauty and skin care, infant \& mom and health care products were the mostly purchased products by cross-border online shopping users in 2016. 60.7\% cross-border online shopping users put product quality the first position. Since melamine event, domestic people lose faith in domestic milk powder, forcing more affordable families to choose cross-border purchasing. 58.6\% groups will consider price factor, as infant $\&$ mom products have a high re-purchase rate. Consumers will purchase from domestic e-commerce websites or physical store if there is not much price difference. In one word, high quality and inexpensive is infant \& mom groups' demand for products. In order to ensure that the goods source is positive and at the same time cut down product price to realize high quality and inexpensive and increase users' adherence, mia.com purchases such brands only from brand agent or general agent and place of origin, making sure real brands are imported and that strict supply chain is controlled. For example, directly mailed milk powder is purchased by local teams and delivered according to the daily order. Every order has an exclusive international shipping number, which is traceable, able to ensure product quality.

2) Seek for products required by buyers through the online "Grass-planting machine": Mia.com opened the "grass-planting machine" on the PC client on March 3, 2015, aiming to get the feedbacks from various customers to rapidly improve and enhance our own services and increase the quality of user experience. Customers can follow the interested goods in the "grass-planting machine", and miyababy will determine the online special offer products according to the vote of customers. Thus, Mia.com gives customers right to select own expected goods of sales, and the online goods of sales can be better matched with customer's "taste" to really meet their demands for products. It is not only save costs of logistics, storage and distribution by putting online the oversea or imported products of high quality for sales directing to the target needs, but also realizes anti-driving of customer's need, so that they would buy on own initiative; in addition, the function of sharing goods comments on Mia.com makes the customers be the sale consultants to successfully bring the online interaction to different consumer groups.

\section{B. Low Cost to Satisfy Customer's Needs and Wants}

The second $\mathrm{C}$ to be considered in $4 \mathrm{C}$ principles is the customer cost. For consumers in the B2C market, the customer cost does not only refer to the product price, which should also include the time, energy, and physical power spent on buying. Therefore, the customer cost should consist of the monetary cost, time cost, mental cost and physical power cost. In order to maximize the customer's satisfaction, Mia.com has given sufficient consideration to the "total customer cost" that the customers would like to pay during preparation of marketing plans.

Firstly, in respect to the monetary cost, Mia.com has been concentrated on CBEC since 2014, which has joined the Ningbo Free Trade Zone, the Guangzhou Free Trade Zone and the Chongqing Free Trade Zone to prepared sufficient standard products and hot best purchases, and it adheres to the method of direct delivery from the customs supervision warehouse to customers, that is, the goods are directly sent from the bonded warehouse after customers place orders on the platform, and it can save the time in international logistics and international freight so as to lower the product price. Since issuance of the CBEC new policy, diapers have been imposed with additional $11.7 \%$ tax, but Mia.com still keeps the farming of tax to maintain the customer interests so as to increase adhesiveness.

Secondly, in respect to the mental and time costs, consumers generally need to spend a lot of time and effort to visit a variety of websites to collect complete information of a product. Therefore, the operators should invest certain resources to enhance the popularity of the website and improve the information search capability of the website, and to. Mia.com launched a price war in the entire CBEC market by the most sensitive brands and goods in March 2015, which has directly set the pricing system (especially for well-known brands such as Merries) at the least significant end, for example, Merries was sold at RMB 68 based on subsidies, and this has shocked the whole industry and subverted the original price positioning of some platforms. The GMV (gross merchandise volume) within 3 days exceeded RMB 300 million, which has renewed a sales record of vertical mother and baby e-commerce with this turnover 3 times the overall GMV of October 2014. Thus, Mia.com has quickly known by consumers and established our own position in the industry. It has also maintained an over $70 \%$ repurchase rate for a long time, and this is enough to indicate consumer's cognition.

Finally, in terms of physical cost, physical cost saving should be one of the advantages of online marketing. 
Consumers can buy oversea products without going abroad and receive goods without stepping out of own apartment. The home delivery service is especially convenient for mothers and babies.

\section{Convenience to Buy}

The third $\mathrm{C}$ of the $4 \mathrm{C}$ principles is focused on assisting consumers to buy their interested goods. For consumers, online shopping should be of such conveniences that are not available in conventional shopping as easily order, easy choice, easy communication, easy payment and easy collection of goods. Mia.com can fast guide consumers to get to their expected shopping areas by the shopping navigation on the website to make ordering more convenient, and it also provides various contact ways, such as customer services in the WeChat client, micro-blog client and on the website, so that consumers can communicate with Mia.com whenever and wherever possible; in addition, such modes of payment as Alipay, WeChat payment and bank card payment can save the trouble of exchange settlement, foreign current purchase and credit card fraud that may be caused by purchasing in oversea e-commerce websites, and the direct delivery from bonded areas can provide consumers with shorter period for waiting. These are the good experiences that Mia gives to the consumers.

1) Simple operation of the user page: Mia inherits the principle of "convenient shopping for consumers" in web page design and purchase procedure and attaches great importance to customer experience in terms of web page and commodity quantity, etc.

The web page is simply classified. Mia is divided into eight categories like paper diapers/milk powder, pregnant mother supplies, beauty products and furniture, among which the most popular and best-selling milk powder and paper diapers are separately listed at a striking position of the front page; and the search bar enables the search to be quicker and more convenient. By taking paper diapers for an example, the customers only need to add the preferred commodities into the online shopping cart and upload the ID card number and the front and back information when buying something for the first time and then they can sit back at home and wait for a surprise from abroad. As there is no need to consider language barrier, foreign exchange settlement and sale by credit card and damage and loss of articles in the transport process, the cross-border shopping is convenient and reassured just like domestic Jingdong shopping and all the process is clear and simple. Surely, the registration process is also simple. You only need to enter mobile phone number, verification code and password. Even a fresh hand also easily gets registered.

2) Simple Procedures for purchasing with Mia APP: The mothers and infants are naturally the mobile population. Therefore, Mia attaches more importance to the development of APP client. Currently, more than 1 million users have downloaded APP, and the proportion of sales volume reaches $75 \%$ (the data given when the website was just online in 2013). On the bran-new page of commodity searching function, the users can quickly match the current special offers according to commodity category so as to enable the mothers to easily complete shopping and place orders while looking after children.

However, the palmtop seckilling is a scare buying channel for displaying ultra-low discounts which is created by Mia. About ten hot-sale single products are recommended every day with a price preference that is as low as $10 \%$. It is an unmissable shopping channel for the hot mothers. The "popular and hot-sale products" are the bargain goods launched by Mia each day. Three hot-sale single products that have extremely high cost performance are selected every day and they are overfavoured by hot mothers.

\section{Effective Communication with Customers}

The fourth $\mathrm{C}$ in $4 \mathrm{C}$ principles is communication. The constant communication with consumers helps an enterprise create a competitive advantage. The network-based interactive marketing emphasizes that an enterprise takes advantage of various network marketing tools to realize two-way interactive exchange with the consumers. The marketing based on 4C principles replaces the traditional sales promotion with communication so that the consumers actively acquire the information related to the commodities by all means and make positive response to the information and thus a trust relationship is established with the consumers. Continuous communication is required with the consumers so as to cultivate the consumers into the fans.

The online "Mia Moments" launched by Mia as well as the offline strategic investment in children's indoor amusement brand YuYuTo, and strategic cooperation with Amcare medical institutions aims to strengthen communication with the consumers while the sold products and strategic deployment are continuously adjusted.

The new edition of "Mia Moments" highlights the overall interest of the client, optimizes the original operation to be quicker and enriches the interactive exchange function at the client. "Mia Moments" provides moms with a professional platform to communicate product use experience and parenting knowledge with each other, giving users a new social experience which integrates shopping, exchange learning and interactive entertainment together rather than simple shopping and further emphasizing on users' participation. Users can optionally follow popular people or add as friend to each other and view their recent dynamics at any time. Furthermore, users can also save "Mia beans" by the means such as posting a picture and interacting with others to level up in the "Mia Moments". Higher-level Mia fans may be directly proposed as popular people. Through "Mia Moments", users can not only share their shopping list by pictures and texts but also directly add brand labels which may link to the product page to the pictures, so as to share their favored goods with others in an intuitive and fast way.

\section{ICBEC -MiA’s MARKETING TREND IN FUTURE}

At present, although the marketing philosophy of "customers first" advocated by 4C marketing theory has already been integrated into real Mia network marketing and certain efficiency \& benefit have been achieved, e.g. the price war involving "a piece of diaper" builds up Mia's status of industry leader and $70 \%$ repurchase rate proves effectiveness 
of its philosophy of "customer demand as the starting point"; currently, many safety and quality problems involving cross-border online shopping still exist. Additionally, ICBEC needs to face public policy fluctuation. For example, implementation of China's new policy on ICBEC on April 8, 2016 which cancels exemption amount, i.e. all commodities need to pay certain proportion of CBEC consolidated tax, has certain impact on Mia's ICBEC enterprises giving priority to bonded warehouse. Compared with traditional trade, price advantage has reduced.

According to iResearch data, among top five factors influencing cross-border user's cross-border shopping, price is just one of the metrical factors. What's more important is product quality and richness. Therefore, if Mia wants to keep sustainable development in mother and baby products market, it must give prominence to product quality and enrich more long-tail products not just diaper and milk powder.

Liu Nan, Mia's CEO, was accompanied to visit Korea and met with high levels from various famous Korean brands. Furthermore, deep cooperation agreements were established with dozens of Korean cosmetic brands. This indicates that Mia will be fully dedicated to cosmetics and further expand its product categories.

In October 2015, Mia's first offline store was opened for business in Hainan Tianyu Hotel, a top parent-child hotel in China. This not only is a bold try for Mia with respect to offline store but also puts forward a totally new concept of “one-stop parent-child travel solution”. In December 2015, Mia Parent-child Channel was officially launched. It indicates that Mia starts to march into infants \& children service sector.

\section{ACKNOWLEDGMENT}

Fund Programs: 2015 Guangdong Province Key Platform and Scientific Research Project (2015GXJK194), Guangdong Province Quality Project E-commerce Foundation Excellent Course (2016JP008)

\section{REFERENCES}

[1] Schultz. Integrated Marketing Communications [M]. Beijing: Chinese Financial \&Economic Publishing House, 2005.

[2] Li Jing, Wei Peiwen. Introduction to E-Commerce [M]. Beijing: Tsinghua University Press, 2016.

[3] Zheng Haohao, Cheng Yasha. Study on Development Situation, Problems and Countermeasures of ICBEC [J]. Guide to Business, 2016(9).

[4] Zhao Yixin. Feasibility Analysis on "All-Port Customs Clearance” Mode for ICBEC [J]. Modern Business, 2016(4)

[5] 2016 Research Report for Chinese ICBEC Retail Industry, iResearch

[6] Jin Hong, Lin Xiaowei. Development Pattern and Strategy Suggestions for Chinese CBEC[J]. Macroeconomics, 2015(9)

[7] Yang Jianzheng, Liu Han. Investigation and Analysis on CBECApplication Situation of Chinese Enterprises of Varying Sizes [J]. Contemporary Economy \& Management, 2014(1) 